\title{
BMJ Open Approaches to supporting lactation and breastfeeding for very preterm infants in the NICU: a qualitative study in three European regions
}

\author{
Mercedes Bonet, ${ }^{1,2,3}$ Emanuela Forcella, ${ }^{4}$ Béatrice Blondel, ${ }^{1,2,3}$ \\ Elizabeth S Draper, ${ }^{5}$ Rocco Agostino, ${ }^{6}$ Marina Cuttini, ${ }^{7}$ Jennifer Zeitlin ${ }^{1,2,3}$
}

To cite: Bonet $M$, Forcella $E$, Blondel B, et al. Approaches to supporting lactation and breastfeeding for very preterm infants in the NICU: a qualitative study in three European regions. BMJ Open 2015;5:e006973.

doi:10.1136/bmjopen-2014006973

- Prepublication history and additional material is available. To view please visit the journal (http://dx.doi.org/ 10.1136/bmjopen-2014006973).

Received 21 October 2014 Revised 26 February 2015 Accepted 27 February 2015

CrossMark

For numbered affiliations see end of article.

Correspondence to

J Zeitlin;

jennifer.zeitlin@inserm.fr

\section{ABSTRACT}

Objectives: To explore differences in approaches to supporting lactation and breastfeeding for very preterm infants in neonatal intensive care units (NICU) in 3 European regions.

Design: Qualitative cross-sectional study carried out by means of face-to-face semistructured interviews. Verbatim transcripts were coded using a theoretical framework derived from the literature and supplemented by data-driven concepts and codes.

Setting: 4 purposively selected NICUs in each of 3 European regions in 2010 (lle-de-France in France, Lazio in Italy, and the former Trent region in the UK).

Participants: NICU staff members $(n=22)$.

Results: Policies and practices for managing mother's own milk for very preterm babies differed between regions, and were much more complex in Ile-de-France than in the Trent or Lazio regions. Staff approaches to mothers to initiate lactation differed by region, with an emphasis on the nutritional and immunological value of human milk in the Trent region and on the 'normalising' effect of breastfeeding on the motherchild relationship in Lazio. French and English staff expressed conflicting opinions about the use of bottles, which was routine in Italy. Italian informants stressed the importance of early maternal milk expression and feeding, but also mentioned discharging infants home before feeding at the breast was established. In Ile-deFrance and Trent, successful feeding from the breast was achieved before discharge, although this was seen as a factor that could prolong hospitalisation and discourage continued breastfeeding for some women.

Conclusions: Targeted health promotion policies in the NICU are necessary to increase the number of infants receiving their mother's milk and to support mothers with transfer of the infant to the breast. Integrating knowledge about the different approaches to lactation and breastfeeding in European NICUs could improve the relevance of recommendations in multiple cultural settings.

\section{INTRODUCTION}

Very preterm infants born before 32 weeks of gestation-about $1.5 \%$ of total births in Europe $^{1}$-are at high risk of respiratory,
Strengths and limitations of this study

- By exploring lactation and breastfeeding practices in neonatal units in diverse cultural settings, our study raises questions about the success of current strategies for ensuring successful lactation and breastfeeding during the baby's hospitalisation and after discharge.

- We used the same interview guide, a common code book and coding cross-checks to reduce the differences in the interpretation of our results related to our multicultural samples. Thus, despite linguistic and cultural differences, our qualitative study was able to reveal similarities and differences in policies and attitudes.

- Our informants were actively involved in lactation and breastfeeding promotion and support at the bedside, and their views may be different from those of other staff members. However, we hypothesised that our informants could accurately describe the policies and practices in their unit.

gastrointestinal and neurodevelopmental complications in the neonatal period ${ }^{2-4}$ and childhood. ${ }^{3}{ }^{5}$ Human milk is widely recommended as the best way to feed these infants, ${ }^{6-9}$ as it meets most of their nutritional requirements, reduces the risk of infection, necrotising enterocolitis and allergies, and may have a positive effect on cognitive development. ${ }^{9-11}$ Very preterm infants also benefit from the skin-to-skin contact with their mothers during breastfeeding, as shown by better physiological stability. ${ }^{12}$ Further, milk expression and breastfeeding present an opportunity for parents, particularly mothers, to be actively involved in their child's care during prolonged hospitalisation in the neonatal intensive care unit (NICU). ${ }^{13} 14$

A previous area-based study, the MOSAIC study, ${ }^{15}$ aimed at comparing medical practices and organisation of care for very 
preterm infants in Europe, found wide variations in very preterm infants receiving human milk at discharge from the NICU in 2003. ${ }^{16}$ Rates ranged from $70 \%(18 \%$ exclusively human milk) in the Lazio region in Italy, to $35 \%(29 \%)$ in the former Trent region in the UK, and $24 \%(14 \%)$ in the Ile-de-France region in France. Other single-country studies confirm the variability in human milk feeding rates for infants at discharge home from the NICU. Data from neonatal networks showed rates of $66 \%$ in Italian high-risk infants, ${ }^{17}$ and of about $50-60 \%$ in the $\mathrm{USA}^{18} 19$ with important variations between NICUs (20-90\%), and across gestational ages and birth weights $(30-70 \%)$. Population-based data from Sweden showed higher rates: $86 \%$ of very preterm infants received human milk feedings at 2 months postnatal age and $60 \%$ at 6 months. ${ }^{20}$

These differences may reflect maternal and infant clinical and sociodemographic characteristics ${ }^{16}{ }^{18-20}$ as well as the country's cultural context. For example, the MOSAIC study found a correlation between NICU rates of human milk feeding and overall breastfeeding rates at the country level. ${ }^{16}$ However, differences may also relate to the degree of promotion and support by NICU staff and to unit policies to facilitate lactation and breastfeeding. ${ }^{21}{ }^{22}$ Providing mother's own milk to very preterm infants is challenging for both mothers and healthcare personnel. As very preterm babies initially do not have the ability to suck from the breast, their mothers must start expressing soon after birth and pump many times a day for weeks to provide their milk and maintain lactation before the infant can be put to the breast. ${ }^{21}{ }^{22}$ They may face difficulties initiating lactation, because their ability to produce milk may be compromised by the preterm birth itself, ${ }^{23}$ or by its association with obstetric (multiple birth, caesarean delivery) or maternal (eclampsia, admission to intensive care) complications. ${ }^{16} 18$ In addition, the introduction of oral feedings for these infants is complex as the sucking capabilities of the very preterm infants are not comparable with those of term infants until the 33rd or 34th week of postmenstrual age. ${ }^{24}$ Most very preterm infants need to be initially fed via a nasogastric tube, then gradually introduced to sucking feeds, by bottle or alternative techniques (cup, syringe or finger-feeding). This process may be further complicated for infants with severe health complications.

Current recommendations for lactation and breastfeeding promotion and support in the $\mathrm{NICU}^{25-29}$ include: specific staff training, information about the benefits and challenges of provision of mother's milk and breastfeeding, avoiding mother-infant separation, promoting skin-to-skin care, encouraging the use of bottle substitutes, helping mothers to initiate milk expression early after birth, and facilitating access to breast pumps.

A few qualitative studies have investigated the opinions of NICU staff on lactation and breastfeeding and found that supportive unit policies, as well as the availability of breast pumps, educational material, lactation consultants and staff training, were viewed as facilitators, while inconsistent or insufficient support from colleagues ${ }^{30}$ and the need to monitor milk intakes ${ }^{31}$ were viewed as barriers.

We aimed to explore to what extent differences in health professionals' attitudes and practices about lactation and breastfeeding in neonatal units may contribute to the wide variation in rates of human milk feedings across European regions. This qualitative study sought to investigate barriers and facilitators for practices supporting the provision of human milk, lactation and breastfeeding of very preterm infants in neonatal units in three regions in France, Italy and the UK, which had different rates of human milk feedings at hospital discharge, according to the MOSAIC study findings. ${ }^{16}$

\section{METHODS}

\section{Study population}

A purposive sample of four neonatal units was selected in each of three European regions: Ile-de-France in France, Lazio in Italy and the former Trent region in the UK. The selection aimed to ensure geographical variability (city and suburbs), maternal sociocultural diversity (based on data on maternal age, parity, percentage of foreign mothers and census tract characteristics), and variation in human milk feedings at discharge from the neonatal unit within each region based on the results of the MOSAIC study. ${ }^{16}$ An invitation letter was sent to the head of each unit to inform them about the study and ask for permission to approach health professionals within the unit. All invited units agreed to participate in the study.

\section{Interviews}

Semistructured, face-to-face interviews were carried out with the healthcare professionals deemed by the head of the unit to have the most knowledge about lactation and breastfeeding. Grouped interviews were carried out when more than one person by unit was assigned.

The interview guide (see online supplementary file S1) was organised chronologically from antenatal counselling to discharge from the NICU and covered routine procedures during the various stages of the process leading to breastfeeding in the very preterm infant. The interviewer prompted items in each section if not mentioned spontaneously by interviewees. Before starting the interview, respondents were told that all questions concerned very preterm infants. Respondents also completed a unit description sheet detailing the structural characteristics of the unit and its policies related to lactation and breastfeeding. Data collection instruments were pretested in three NICUs.

The interviews were performed in local languages in the NICUs between March and July 2010 by MB in Ile-de-France and the Trent region, and by EF and $\mathrm{MB}$ in Lazio. They lasted 1-2 $\mathrm{h}$, and were audiotaped and 
transcribed verbatim. Filed notes were made after the interview.

Ethics committee approval and written informed consent were obtained in the Trent region. This was not required in Lazio or Ile-de-France.

\section{Data analysis}

The interview transcripts were analysed using the framework approach, ${ }^{32}$ which makes it possible to take into account a priori issues and research questions linked to the progression of stages from antenatal counselling to transfer of the baby to the breast. This approach is increasingly used in applied healthcare policy research when specific a priori questions have to be explored. ${ }^{33}$ It is also well suited to mixed methods research when quantitative data are also available.

MB transcribed the interviews from Ile-de-France and the Trent region, and EF those from Lazio. The two researchers then read and reread all the transcripts to become familiar with the data collected. A working analytical framework was identified using codes and categories derived from the study main research questions as included in the interview guide. The framework was further enhanced by a review of the literature regarding lactation and breastfeeding promotion programmes, ${ }^{34-37}$ maternal ${ }^{13} 2126$ and staff ${ }^{30} 31$ views on lactation and breastfeeding the very preterm infant, as well as barriers and facilitators related to decision-making in clinical practice. ${ }^{38}$ New codes and categories emerging from the data were added during the coding of the interviews, while some of the initial codes were modified in an iterative process.

Charting data into the framework matrix focused on the principal barriers and facilitators categories related to the attitudes and practices of health professionals. Interpretation of data involved identifying differences and similarities between the regions, finding associations within themes and subthemes, and identifying links that could explain the findings of the quantitative data from the MOSAIC study. ${ }^{16}$ Key concepts were illustrated using the respondents' own words (translated into English by professional translators), as advocated as a mean of staying 'true' to the data. ${ }^{32}$ Contextual information about structural factors and unit policies related were also abstracted from the interviews.

Coding cross-checks were performed by double coding of one interview from each region and by secondary reviews of all interviews by another coauthor (JZ for the Trent Region, BB for Ile-de-France, MC for Lazio). Discrepancies between authors were solved through consensus agreement. NVivo software V.9 (QSR International, Australia) was used for data coding and charting.

We then selected barriers and facilitators that differed in at least two of the regions, including the interpretation of evidence, views about the patients' role in decisionmaking and their own self-efficacy, as well as environmental factors such as resources and organisational constraints. We grouped them into 11 subthemes related to lactation initiation (2 themes), management of human milk (2), lactation maintenance (4), and organisational factors (3). Online supplementary table S2 provides the framework classifications for the subthemes.

\section{RESULTS}

Table 1 shows the interviewees' profile and the characteristics of the units included in the study. A total of 22 professionals participated. Nurses $(\mathrm{N}=8)$ participated in interviews in all regions; lactation experts $(\mathrm{N}=7)$ (lactation consultant or infant feeding coordinator) were interviewed in Ile-de-France and the Trent region, and physicians $(\mathrm{N}=7)$ in Lazio. All units were tertiary-level units, except one level II unit in the Trent region. In the participating units, the proportion of infants receiving human milk at discharge in 2003

\begin{tabular}{|c|c|c|c|}
\hline & Ile-de-France (4) & Trent (4) & Lazio (4) \\
\hline \multicolumn{4}{|l|}{ Interviewee professional background } \\
\hline Nurse/family care coordinator & 4 & 2 & 2 \\
\hline Lactation expert ${ }^{\star}$ & 2 & 5 & 0 \\
\hline Paediatrician or obstetrician & 0 & 0 & 7 \\
\hline \multicolumn{4}{|l|}{ Characteristics of the units } \\
\hline Tertiary level unit & 4 & 3 & 4 \\
\hline Number of neonatal units with more than 300 admissions/year & 4 & 3 & 3 \\
\hline More than $50 \%$ of infants breastfed at discharge in 2003 & 0 & 0 & 4 \\
\hline More than $50 \%$ of infants breastfed at discharge in 2009 & Not available & 1 & 4 \\
\hline \multicolumn{4}{|l|}{ Personnel, accreditation and protocols } \\
\hline Number of units with a lactation expert* & 2 & 3 & $1 \dagger$ \\
\hline BFHI commitment or stage 1 (year of accreditation) & 0 & $3(2010)$ & $1(2007)$ \\
\hline Written protocols for human milk use or breastfeeding in very preterm infants & 1 & 1 & 2 \\
\hline
\end{tabular}


varied from less than $35 \%$ in Ile-de-France, to less than $50 \%$ in the Trent region, and more than $55 \%$ in Lazio. In 2009, the same units continued to have similarly high or low rates of human milk feedings when compared with other units within their region. Rates did not overlap between regions. Three units in Trent and one unit in Lazio had started the accreditation process for the Baby Friendly Hospital Initiative label.

The following sections report results with supporting quotations where barriers and/or facilitators related to initiation of lactation, management of human milk, lactation maintenance and organisational factors differed in at least two of the regions. Online supplementary table S3 provides a summary of these results.

\section{Initiation of lactation}

The timing and approaches used to inform mothers about lactation and breastfeeding differed by region. Health professionals in Ile-de-France and the Trent region reported that they had deliberated about the best time to discuss lactation and breastfeeding with the mother after delivery. This was perceived as a potential barrier, as it could delay the provision of information to the mothers, as remarked below by an English lactation expert:

Some staff will encourage [early human expression], some will wait till the mother feels a little bit better. (lactation expert, UK)

French professionals also appeared to be concerned with allowing maternal choice and avoiding guilt should the mother decide not to breastfeed, as illustrated below:

[giving advice about breastfeeding] bothers me enormously because when you give advice, you may seem pushy: do this, do that. So, I just give them the information and then they make their decision. (lactation expert, France)

In contrast, English respondents emphasised the value of human milk for the preterm infant, and reported efforts to convince mothers about the benefits of human milk and persuade them to start expression:

Here we are successful getting mums to express... because the medical team and the nurses work together to emphasize the fact that [human milk expression] is the best thing they can do for their baby. (nurse, UK)

In Lazio, respondents placed less emphasis on discussing the decision to express or breastfeed with the mothers, and showed a strong expectation that all women would breastfeed because of its importance for strengthening the maternal role and the mother-infant relationship:

The idea of having this task, of at least expressing and bringing the milk, makes [the mothers] feel important to their baby. (doctor, Italy)
The discussion of expression and breastfeeding with the mother after delivery was perceived positively, both for the mother and the health professional:

This is perhaps the only time, when you can give pleasant information...It is quite rewarding for those who give the information, because otherwise all the other information is a bit...challenging. (doctor, Italy)

Thus, Italian respondents emphasised the need to start expression of mother's own milk as soon as possible, and early feeding:

Because the crucial point is to very soon tell the mother to start stimulating the breast and expressing milk as soon as possible. (doctor, Italy)

\section{Management of human milk}

The differences in unit policies for human milk management are summarised in table 2. In Ile-de-France, units used pasteurised milk or, if using fresh milk, performed systematic human cytomegalovirus (HCMV) testing and bacteriological analyses, and only allowed storage for less than $48 \mathrm{~h}$. In the Trent region, all units used fresh or frozen-thawed human milk and stored human milk up to $48 \mathrm{~h}$. No unit in this region used systematically pasteurised milk, checked for maternal HCMV serology, or performed systematic bacteriological analysis of the milk. Practices in Italy varied between units. French health professionals appeared more concerned with the risks of infection transmitted via human milk than professionals in the other two regions:

We can't just give fresh milk like that, without any bacteriological testing. (nurse, France)

In contrast, English and Italian informants relied primarily on making sure mothers followed hygiene recommendations for pumping and transporting their milk, reporting no systematic policies for infection screening. Bacteriological analyses were carried out on the milk only in case of suspected infection.

All French units had access to pasteurised milk. This was perceived as a resource that allowed more infants to be fed human milk, either because donor milk could be used if the mother was not expressing or because the mother's own milk could be pasteurised in the unit:

If she [the mother] doesn't want to give her milk, it doesn't matter that much because we have the milk bank. (nurse, France)

Donor milk was not available in the English units included in this study, and its access was limited in the Italian units. Donor milk was seen as positive in the one Italian unit with access to a milk bank, where donor milk was used mainly when the mother's own milk was not available. 
Table 2 Structural and policy factors related to lactation and breastfeeding practices in neonatal units

\begin{tabular}{|c|c|c|c|}
\hline & \multicolumn{3}{|l|}{ Number of units } \\
\hline & Ile-de-France (4) & Trent (4) & Lazio (4) \\
\hline \multicolumn{4}{|l|}{ Use of fresh, frozen-thawed or pasteurised mother's own milk } \\
\hline \multicolumn{4}{|l|}{ Use of fresh milk for infants less than 32 weeks } \\
\hline Yes & 2 & 4 & 3 \\
\hline No-only pasteurised milk & 2 & 0 & 1 \\
\hline Use of frozen-thawed milk & 0 & 4 & 2 \\
\hline Storage fresh milk up to $48 \mathrm{~h}$ & 0 & 4 & 1 \\
\hline Systematic HCMV screening of all mothers & 4 & 0 & 1 \\
\hline \multicolumn{4}{|l|}{ Type of milk given if positive HCMV screening } \\
\hline Pasteurised milk & 4 & 0 & 0 \\
\hline Frozen-thawed milk & 0 & 0 & 1 \\
\hline Systematic bacteriology analysis of fresh milk & 4 & 0 & 0 \\
\hline \multicolumn{4}{|l|}{ Regular access to pasteurised milk } \\
\hline Milk bank & 4 & 1 & 1 \\
\hline On-site pasteurisation unit (for mother's own milk only) & 2 & 0 & 1 \\
\hline \multicolumn{4}{|l|}{ Maintenance of lactation and transfer to the breast } \\
\hline Use of cup/syringe feeding & 4 & 4 & 0 \\
\hline Transfer to breast starts before 33 weeks & 1 & 2 & 4 \\
\hline Pumping/breastfeeding room & 4 & 4 & 2 \\
\hline \multicolumn{4}{|l|}{ Role of units' policies } \\
\hline Visiting hours 24/24 & 4 & 4 & 0 \\
\hline
\end{tabular}

\section{Lactation maintenance and transfer to the breast}

Maintenance of lactation during the infant's hospitalisation in the neonatal unit was recognised as challenging by the French and English informants. In Ile-de-France, health professionals were concerned that unit policies aimed at preventing the transmission of infections, such as pasteurisation of mother's own milk, could be interpreted by mothers as an indication that their milk was tainted, or that they themselves were in some way at fault:

[mother's pasteurized milk] takes a long time to obtain. During this time, the baby receives donor milk or formula. It's very discouraging for the mothers...they have the feeling that their milk has to be purified. (lactation expert, France)

In the Trent region, our informants highlighted difficulties in helping mothers to maintain their milk supply, and the need to improve follow-up of mothers who initiate milk expression:

Making sure that the mother does it better in the long term rather than just focusing on that first week to ten days. We need to be more proactive. (nurse, UK)

In contrast, Italian informants did not express concerns about mothers maintaining milk supply.

The use of alternatives to bottles to support the successful establishment of breastfeeding was also mentioned. All units in Ile-de-France and the Trent region appeared to favour the use of cups or syringes to feed infants until the infant was feeding at the breast, and staff expressed concerns about the use of bottles when the mother had decided to breastfeed:

the problem of the bottle is double-edged, because the parents realize that the baby will take larger quantities, swallow faster, and afterwards it's really an obstacle to putting the baby to the breast. (lactation expert, France)

We are trying to encourage more cup feeding because once you introduce that bottle then...it is easier to move on to formula, isn't it? With the cup they don't tend to think about formula, they will think about breast milk in a cup. (nurse, UK)

However, opinions about bottles were mixed in these regions. Some informants expressed doubts about the existence of teat-nipple confusion among very preterm infants. Bottle feeding was also viewed as reassuring for the mothers and the health professionals, because it allowed them to quantify how much milk the infants were receiving.

No Italian unit used techniques to avoid bottles. In this region, bottles were seen as helpful for feeding high-risk infants, and were often used before babies were put to the breast:

when we see sucking-swallowing coordination we start with the bottle and then afterwards with the breast...

Because the breast is a bit trickier. (doctor, Italy)

In all regions, the importance of viewing support to lactation and breastfeeding as part of professional duties was highlighted. However, French and English 
professionals reported worries that healthcare staff, in particular neonatal nurses, while very good on the technical aspects of infant care, were less attentive to milk supply and breastfeeding:

Even after being made aware, being trained, it is still necessary to have a real desire to support these mothers and devote time to them. (nurse, France)

They [nurses] are very good at their job but...what's missing is making sure that the mum is still expressing well and that there's still milk coming out. (nurse, UK)

In contrast, in Italy, physicians presented the promotion of lactation and breastfeeding in general as a central part of the nurses' job and even of their own job:

We always bear in mind the issue of nutrition. When we provide news about a baby and we say it is doing fine etc... is he/she feeding? your own milk, I recommend you that you keep expressing... it is important that you bring [own milk]. And this is what the nurses do a lot. (doctor, Italy)

French and English professionals brought up a range of difficulties encountered when putting infants to the breast, including difficulties in assessing the infant's ability to feed at the breast and the quantities of milk the infant was receiving. They also identified delays in transferring infants to the breast, reporting that this often occurs after 33 weeks postmenstrual age when most very preterm infants have sucking capabilities comparable with term infants:

We could propose that [the mothers] put the baby to the breast, but, at that level, we still have a lot of work to do...because, in my opinion, we start putting babies to the breast too late. (lactation expert, France)

Staff sometimes don't have the confidence to know when they can reduce that top up and reassure the mother that her baby is getting enough milk from her breast. (lactation expert, UK)

In both these regions, informants described cases where mothers expressed milk to feed their very preterm infant, without the intention of putting the infant to the breast.

In contrast, Italian interviewees emphasised putting the infant to the breast as soon as possible and the "normalising' effect of breastfeeding on the mother-child relationship after a preterm birth. Health professionals focused on the mother's wish to feed from the breast:

The mothers tend to have a strong desire to get the baby to latch on to the breast. They ask you, "but, doctor, when I can start breastfeeding?” (doctor, Italy)

However, staff suggested that mothers may establish feeding at the breast after discharge:
They [staff] tell the mothers "start in the morning [to put the baby at breast], when you are home, during the feed in which you have more [milk], try to get your baby to latch on, gradually." (doctor, Italy)

\section{Organisational factors}

Visiting policies differed by regions. While in all French and English units parents could visit at any time during the day or the night, Italian units had limited visiting hours (table 2). Restrictive policies were justified by lack of space for health professionals to perform clinical procedures or medical rounds while parents are by their infant's cot. In these units, visiting hours were often based on the feeding schedule of the infants, although regular exceptions were made and mothers could stay longer for breastfeeding or skin-to-skin care. These exceptions appeared to be considered by the Italian health professionals as a bonus and an indication of being sensitive to the needs of mothers and infants.

All French and English units had a designated breastfeeding or pumping room, whereas this was the case in only two of the four Italian units (table 2). Absence of privacy for using breast pumps, or while breastfeeding, was seen as a potential barrier in the French and English units, but was not mentioned by our Italian informants:

If they wish to tuck behind the screen, they can; so we do hopefully give them a bit of dignity. (nurse, UK)

French and English informants commented that infants were discharged home only after they had attained adequate and independent oral feeding, and that this discharge strategy could discourage breastfeeding since bottle-fed babies became independent sooner:

We would introduce the bottle because it makes it possible to accelerate discharge from the hospital. (nurse, France)

[the mother] goes down to the bottle because that's what she wants to do and that baby will go home sooner than if she stresses at the end of breastfeeding. (nurse, UK)

This issue was not mentioned in Italy, as most of the infants were fed by bottle during hospitalisation, and might be discharged home before breastfeeding was completely established.

\section{DISCUSSION}

Professional practices and approaches related to lactation and breastfeeding in the neonatal unit varied in European regions, and this variation may contribute to differences in rates of human milk feedings observed in the literature at discharge from the NICU. We identified barriers and facilitators that differed between at least two of the three regions in our study, including the ways that professionals approached mothers about initiating lactation, the assessment of the benefits and risks associated 
with use of fresh versus pasteurised human milk, opinions about the use of bottles for breastfed infants, and unit visiting and discharge policies. These results enrich our understanding of variations in rates of human milk feedings in participating regions, and shed new light on key debates surrounding lactation and breastfeeding practices for very preterm infants.

In the two regions with higher rates of human milk feedings, Lazio and the former Trent region, ${ }^{16} 3940$ health professionals highlighted the importance of breastfeeding for the mother-child relationship and the benefits of fresh human milk; they also stressed early human milk expression, and used less complex practices for managing maternal milk. In Italy this approach may well contribute to the relatively high 'any' human milk feeding rates, but the existence of restricted visiting hours and routine use of bottles prevented exclusive mother's own milk feeding, and feeding from the breast at discharge from NICU. In Trent, highly motivated personnel engaged in promoting the benefits of human milk and the simplicity of procedures for human milk use may have contributed to the higher rates of exclusive human milk feedings. In contrast, personnel in the French region, where rates were lowest, were more attuned to the potential risks of infections associated with human milk feeding, had more complex procedures for the management of human milk, and expressed more concerns about the difficulties of mothers who expressed their milk or breastfed.

None of the models described in this study appeared to guarantee mother's own milk feedings and breastfeeding at discharge for the majority of infants. Policies that promote milk expression do not appear to be sufficient in the long term to help mothers maintain lactation through their infant's hospitalisation and after discharge. Similarly, current practices did not appear to be sufficient to achieve breastfeeding in the NICU before discharge, and this even in places where breastfeeding is generally supported, as in the Italian region.

The variability that we observed in practices for managing mother's own milk is in line with other studies ${ }^{41-44}$ reporting differences between European countries and between neonatal units within countries. Evidence to back up the use of fresh or pasteurised milk for very preterm infants remains inconclusive regarding the risk of infection transmission, ${ }^{45}{ }^{46}$ or modification of the milk's nutritional and immunological properties. ${ }^{47}{ }^{48}$ While adopting a risk-averse stance may seem reasonable in the absence of clear evidence, our results suggest that some procedures for managing mother's own milk may have a negative impact on the general use of human milk use in the neonatal units. Our French respondents expressed concern that procedures for the use of mother's own milk negatively affected mothers' motivation to express by making them feel that their milk needed to be 'purified'. These procedures might also affect their capacity to provide their milk, since short storage times require parents to visit the neonatal unit several times a day. Also, the waiting time for bacteriological results or for pasteurisation of milk was reported to increase the use of formula in some circumstances. In addition, in France, historic problems with blood banks and infection transmission ${ }^{49}$ have shown a long-lasting influence on health professionals and authorities as regards the application of the precautionary principle when using biological products, including fresh human milk.

Health professionals' attitudes and practices related to initiation and maintenance of lactation may be influenced by the availability of pasteurised human milk and milk banks. Milk banks undoubtedly increase use of human milk for infants admitted to neonatal units, especially as exclusive human milk feedings. A recent study in Italy has shown that the presence of a human milk bank in the hospital is associated with higher breastfeeding rates in the NICU, ${ }^{6}$ suggesting that it can positively reinforce the culture of breastfeeding. However, the effect of human milk banks might differ in other cultural settings. Our results suggest that the wider use of donor human milk reported in Ile-de-France appeared to function as a replacement when mothers decided not to express, rather than as a temporary solution when mother's own milk was not available. Availability of donor milk may also negatively affect the French health professionals' motivation to actively encourage women to start expression soon after delivery. In contrast, health professionals in Trent and Lazio were more proactive, as they needed to persuade women to express if their infants were to receive human milk.

Our study raises questions about the role of lactation experts in the NICU. They can certainly help mothers to successfully achieve lactation and breastfeeding and to disseminate knowledge and skills among professionals, particularly in those units where doctors and nurses do not have the expertise, time or motivation to help mothers through lactation and breastfeeding. However, the influence of lactation experts might be more important in contexts where breastfeeding is not the norm and where healthcare professionals do not consider lactation and breastfeeding as part of their role, as illustrated by the Ile-de-France and Trent regions. Their presence might be felt less necessary in units with a different approach, where all staff categories are supposed to support the mothers, as reported in Lazio. Reverse causality cannot be excluded, however, and the availability of lactation experts may lead to delegating lactation and breastfeeding support, with loss of interest and commitment by the rest of the staff.

Finally, we found that transferring very preterm infants to the breast remains a challenging task in all the study regions, although approaches differed. This issue was clearly mentioned by health professionals in the French and English regions, and is consistent with findings from previous studies. ${ }^{30}$ In Italy, some babies seemed to be discharged home before transition to the breast was fully established, which, together with the more liberal use of bottles, may be related to the restrictive visiting policies ${ }^{50}$ that in 
many units limit the time that mothers can spend with their babies. ${ }^{51}$ An Italian study showing that only a small percentage of mothers $(3 \%)$ feed very preterm babies directly at the breast at discharge from hospital ${ }^{17}$ corroborates our findings. Improving procedures for putting babies to the breast is important as this has been found to increase exclusive breastfeeding at discharge from the NICU. ${ }^{52}$

Our results raise questions about the specific support for maintenance of lactation in the NICU and its continuation postdischarge. In particular, postdischarge breastfeeding interventions will depend on how successful mothers are at maintaining established lactation through to discharge from the NICU. Recent recommendations highlight the importance of preparing parents for breastfeeding after hospital discharge and of ensuring access to professional or lay peer counsellors in the community, ${ }^{27}$ but data on breastfeeding practices and maternal experiences after their infant's discharge from the NICU are scarce. This is an important area for future research.

Although the inclusion criteria for the key informants were the same for all units, the professional qualifications of the interviewees differed by region as a result of differences in the organisation of care for supporting lactation and breastfeeding in each region. However, we used the same interview guide across these different contexts, a common code book, and coding cross-checks to reduce the differences in the interpretation of our results related to our multicultural sample. Our study had limitations, however. Our informants were actively involved in promotion of lactation and breastfeeding and support at the bedside, and thus their views may be different from those of other staff members. In the absence of a designated lactation consultant, the head of the unit chose the informant(s) and might have chosen people with a more supportive attitude towards lactation and breastfeeding. However, we hypothesised that our informants could accurately describe the policies and practices in their unit. Our study was not designed to capture the differences in opinion between health professionals within units, and since we had a relatively small sample of units in each region, we could not compare interviewees' views across the same professional categories. Our focus was on themes that differed across regions and not those that emerged from interviews in all regions, such as the importance of having updated knowledge about lactation processes, the training of personnel, antenatal information of the mothers, and the practice of skin-to-skin care and peer-to-peer support. All informants also made some reference to the inconsistent and conflicting advice given to mothers by different staff members, lack of breast pumps and personnel time to support mothers who were expressing or breastfeeding. Finally, our study focused on the views of health professionals, and we cannot assess how maternal attitudes and experiences differed between the regions, and their role in shaping human milk provision and breastfeeding practices and rates.

\section{CONCLUSION}

Attitudes and practices about lactation and breastfeeding in the NICU varied in the three European regions in our study. An understanding of these varied approaches to lactation and breastfeeding provides a starting point for the development of effective recommendations for the use of mother's own milk and promotion of breastfeeding that apply to multiple cultural settings. Our research identified salient differences in approaches to mothers about their decision to initiate lactation and breastfeeding, the perception of risks and benefits of mother's fresh milk, donor milk availability, the role of lactation experts, the use of bottles and discharge policies. However, none of the models described in this study appeared to guarantee breastfeeding for the majority of infants during their hospital stay and after discharge.

\section{Author affiliations}

${ }^{1}$ Inserm UMR 1153, Obstetrical, Perinatal and Pediatric Epidemiology Research Team, (Epopé). Center for Epidemiology and Statistics Sorbonne Paris Cité, Paris, France

${ }^{2}$ DHU Risks in Pregnancy, Paris, France

${ }^{3}$ Paris-Descartes University, Paris, France

${ }^{4}$ Department of International Cooperation, Laziosanità-Agenzia di Sanità Pubblica, Rome, Italy

${ }^{5}$ Department of Health Science, University of Leicester, Leicester, UK

${ }^{6}$ Department for Mother's and Infant's Health, Hospital S. Giovanni CalibitaFatebenefratelli, Rome, Italy

${ }^{7}$ Research Unit of Perinatal Epidemiology, Bambino Gesù Children's Hospital, IRCCS, Rome, Italy

Acknowledgements The authors would like to thank the neonatal units and all doctors, lactation experts and nurses who participated in the interviews. They would also like to thank Priscille Sauvegrain for her thoughtful comments on the manuscript.

Contributors MB developed the interview guide, conducted interviews in Ile-de-France and the Trent region, wrote the first draft of the paper, and approved the final manuscript. BB and JZ contributed to the development of the interview guide and to data interpretation, participated in revisions and approved the final manuscript. EF conducted the interviews in the Lazio region, contributed to data interpretation, participated in revisions and approved the final manuscript. MC, ESD and RA contributed to data interpretation, participated in revisions and approved the final manuscript.

Funding Institut Nationale de la Santé et de la Recherche Médicale (INSERM) and the EPICE research project funded under the European Commission's 7th Framework Programme (259882).

Competing interests None declared.

Ethics approval The Trent Research Ethics Committee in the Trent region.

Provenance and peer review Not commissioned; externally peer reviewed.

Data sharing statement No additional data are available.

Open Access This is an Open Access article distributed in accordance with the Creative Commons Attribution Non Commercial (CC BY-NC 4.0) license, which permits others to distribute, remix, adapt, build upon this work noncommercially, and license their derivative works on different terms, provided the original work is properly cited and the use is non-commercial. See: http:// creativecommons.org/licenses/by-nc/4.0/

\section{REFERENCES}

1. EURO-PERISTAT Project with SCPE and EUROCAT. European Perinatal Health Report. The health and care of pregnant women 
and babies in Europe in 2010: May 2013. http://www.europeristat. com (accessed Sep 2013).

2. Costeloe KL, Hennessy EM, Haider S, et al. Short term outcomes after extreme preterm birth in England: comparison of two birth cohorts in 1995 and 2006 (the EPICure studies). BMJ 2012;345: e7976.

3. Marret S, Ancel PY, Marpeau L, et al. Neonatal and 5-year outcomes after birth at 30-34 weeks of gestation. Obstet Gynecol 2007;110:72-80.

4. Zeitlin J, Draper ES, Kollee L, et al. Differences in rates and short-term outcome of live births before 32 weeks of gestation in Europe in 2003: results from the MOSAIC cohort. Pediatrics 2008;121:e936-44.

5. Larroque B, Ancel PY, Marret S, et al. Neurodevelopmental disabilities and special care of 5-year-old children born before 33 weeks of gestation (the EPIPAGE study): a longitudinal cohort study. Lancet 2008;371:813-20.

6. Arslanoglu S, Corpeleijn W, Moro G, et al. Donor human milk for preterm infants: current evidence and research directions. $J$ Pediatr Gastroenterol Nutr 2013;57:535-42.

7. Agostoni C, Buonocore G, Carnielli VP, et al. Enteral nutrient supply for preterm infants: commentary from the European Society of Paediatric Gastroenterology, Hepatology and Nutrition Committee on Nutrition. J Pediatr Gastroenterol Nutr 2010;50:85-91.

8. American Academy of Pediatrics. Breastfeeding and the use of human milk. Pediatrics 2012;129:e827-41.

9. WHO. Optimal feeding of low-birth-weight infants: technical review. 2006. http://whqlibdoc.who.int/publications/2006/9789241595094_ eng.pdf (accessed Sep 2013).

10. Underwood MA. Human milk for the premature infant. Pediatr Clin North Am 2013:60:189-207.

11. Schanler RJ. Mother's own milk, donor human milk, and preterm formulas in the feeding of extremely premature infants. $J$ Pediatr Gastroenterol Nutr 2007:45(Suppl 3):S175-7.

12. Sizun J, Ratynski N, Jay N, et al. Allaitement maternel et prématurité: intérêts des soins de développement centrés sur l'enfant et sa famille. Spirale 2003/3(no 27), 15-22.

13. Sweet L. Expressed breast milk as 'connection' and its influence on the construction of 'motherhood' for mothers of preterm infants: a qualitative study. Int Breastfeed J 2008:3:30.

14. Flacking R, Ewald U, Nyqvist KH, et al. Trustful bonds: a key to "becoming a mother" and to reciprocal breastfeeding. Stories of mothers of very preterm infants at a neonatal unit. Soc Sci Med 2006;62:70-80.

15. Zeitlin J, Papiernik E, Breart G, et al. Presentation of the European project models of organising access to intensive care for very preterm births in Europe (MOSAIC) using European diversity to explore models for the care of very preterm babies. Eur $\mathrm{J}$ Obstet Gynecol Reprod Biol 2005;118:272-4.

16. Bonet $\mathrm{M}, \mathrm{Blondel} \mathrm{B}$, Agostino $\mathrm{R}$, et al. Variations in breastfeeding rates for very preterm infants between regions and neonatal units in Europe: results from the MOSAIC cohort. Arch Dis Child Fetal Neonatal Ed 2011:96:F450-2.

17. Davanzo R, Monasta L, Ronfani L, et al. Breastfeeding at NICU discharge: a Multicenter Italian Study. J Hum Lact 2012;29:374-80.

18. Lee HC, Gould JB. Factors influencing breast milk versus formula feeding at discharge for very low birth weight infants in California. $J$ Pediatr 2009;155:657-62, e1-2.

19. Powers NG, Bloom B, Peabody J, et al. Site of care influences breastmilk feedings at NICU discharge. J Perinatol 2003;23:10-13.

20. Flacking $\mathrm{R}$, Nyqvist $\mathrm{KH}$, Ewald $\mathrm{U}$. Effects of socioeconomic status on breastfeeding duration in mothers of preterm and term infants. Eur J Public Health 2007;17:579-84.

21. Mclnnes RJ, Chambers J. Infants admitted to neonatal unitsinterventions to improve breastfeeding outcomes: a systematic review 1990-2007. Matern Child Nutr 2008:4:235-63.

22. Renfrew M, Craig D, Dyson L, et al. Breastfeeding promotion for infants in neonatal units: a systematic review and economic analysis. Health Technol Assess 2009;13:1-170.

23. Hartmann P, Cregan M. Lactogenesis and the effects of insulindependent diabetes mellitus and prematurity. $J$ Nutr 2001:131:3016S-20S.

24. Lau C. Oral feeding in the preterm infant. NeoReviews 2006;7: e19-26.

25. Spatz DL. Ten steps for promoting and protecting breastfeeding for vulnerable infants. J Perinat Neonatal Nurs 2004;18:385-96.

26. Nyqvist $\mathrm{KH}$, Kylberg $\mathrm{E}$. Application of the baby friendly hospital initiative to neonatal care: suggestions by Swedish mothers of very preterm infants. J Hum Lact 2008;24:252-62.

27. Nyqvist $\mathrm{KH}$, Haggkvist AP, Hansen MN, et al. Expansion of the ten steps to successful breastfeeding into neonatal intensive care: expert group recommendations for three guiding principles. J Hum Lact 2012;28:289-96.

28. The Academy Of Breastfeeding Medicine. Clinical Protocol Number \#12. Transitioning the Breastfeeding/Breastmilk-fed Premature Infant from the Neonatal Intensive Care Unit to Home, 2004. http://www. bfmed.org/resources/download.aspx?filename=protocol_12.pdf (accessed Sep 2013]

29. UNICEFUK. UNICEF UK Baby Friendly Initiative best practice standards for establishing and maintating lactation and breastfeeding in neonatal units. http://unicef.org.uk/Documents/Baby_Friendly/ Guidance/neonatal_standards.pdf?epslanguage=en (accessed Sep 2013).

30. Cricco-Lizza R. Rooting for the breast: breastfeeding promotion in the NICU. MCN Am J Matern Child Nurs 2009;34:356-64.

31. Mclnnes RJ, Shepherd AJ, Cheyne $\mathrm{H}$, et al. Infant feeding in the neonatal unit. Matern Child Nutr 2009;6:306-17.

32. Ritchie J, Lewis J. Qualitative research practice: a guide for social science students and researchers. London: SAGE Publications Ltd, 2003:336.

33. Gale NK, Heath G, Cameron E, et al. Using the framework method for the analysis of qualitative data in multi-disciplinary health research. BMC Med Res Methodol 2013;13:117.

34. Alexandre $\mathrm{C}$, Bomy $\mathrm{H}$, Bourdon $\mathrm{E}$, et al. [Lactation counselling support provided to mothers of preterm babies who intend to breastfeed. Evaluation of an educational intervention in a level III perinatal unit]. Arch Pediatr 2007:14:1413-19.

35. Dall'Oglio I, Salvatori G, Bonci E, et al. Breastfeeding promotion in neonatal intensive care unit: impact of a new program toward a BFH for high-risk infants. Acta Paediatr 2007;96:1626-31.

36. Montgomery D, Schmutz N, Baer VL, et al. Effects of Instituting the "BEST Program" (Breast Milk Early Saves Trouble) in a Level III NICU. J Hum Lact 2008;24:248-51.

37. Bernaix LW, Schmidt CA, Arrizola M, et al. Success of a lactation education program on NICU nurses' knowledge and attitudes. J Obstet Gynecol Neonatal Nurs 2008;37:436-45.

38. Legare F, Ratte S, Gravel K, et al. Barriers and facilitators to implementing shared decision-making in clinical practice: update of a systematic review of health professionals' perceptions. Patient Educ Couns 2008;73:526-35.

39. Franco F, Di Lallo D, Farchi S, et al. UTIN online: Rapporto dimissioni 2010: Network dei centri di Terapia Intensiva Neonatale del Lazio, 2011. http://www.asplazio.it/servizi/files/utin/Rapporto_ UTIN_2010.pdf (accessed Sep 2013).

40. Field DJ, Manktelow BM, Boyle EM, et al. The Neonatal Survey and Yorkshire Neonatal Network Report 2010, 2011. https://www2.le.ac. uk/departments/health-sciences/research/timms/documents/ the-neonatal-survey-report-2010.pdf (accessed Sep 2013).

41. Buxmann H, Falk M, Goelz R, et al. Feeding of very low birth weight infants born to HCMV-seropositive mothers in Germany, Austria and Switzerland. Acta Paediatr 2010;99:1819-23.

42. Cossey V, Johansson AB, de Halleux V, et al. The use of human milk in the neonatal intensive care unit: practices in Belgium and Luxembourg. Breastfeed Med 2012;7:302-6.

43. Omarsdottir S, Casper C, Akerman A, et al. Breastmilk handling routines for preterm infants in Sweden: a national cross-sectional study. Breastfeed Med 2008;3:165-70.

44. Bonet M, Durox M, Blondel B, et al. Management of mother's own milk for very preterm infants in tertiary-level neonatal units in the Ile-de-France region in France. Breastfeed Med 2014;9:47-8.

45. Lombardi G, Garofoli F, Manzoni P, et al. Breast milk-acquired cytomegalovirus infection in very low birth weight infants. J Matern Fetal Neonatal Med 2012;25(Suppl 3):57-62.

46. Schanler RJ, Fraley JK, Lau C, et al. Breastmilk cultures and infection in extremely premature infants. J Perinatol 2011;31:335-8.

47. Ewaschuk JB, Unger S, Harvey S, et al. Effect of pasteurization on immune components of milk: implications for feeding preterm infants. Appl Physiol Nutr Metab 2011;36:175-82.

48. Tully DB, Jones F, Tully MR. Donor milk: what's in it and what's not. $J$ Hum Lact 2001:17:152-5.

49. Moutel G, Hergon E, Duchange N, et al. [Theoretical risk management and legitimacy of the precautionary principle in medicine. Look back at HIV contamination through blood transfusion in France, twenty years ago]. Transfus Clin Biol 2005;12:38-44.

50. Greisen G, Mirante N, Haumont D, et al. Parents, siblings and grandparents in the neonatal intensive care unit. A survey of policies in eight European countries. Acta Paediatr 2009;98:1744-50.

51. Cuttini M, Chiandotto V, Barba $\mathrm{BD}$, et al. Visiting policies in neonatal intensive care units: staff and parents' views. Arch Dis Child Fetal Neonatal Ed 2000;82:F172

52. Pineda R. Direct breast-feeding in the neonatal intensive care unit: is it important? J Perinatol 2011;31:540-5. 